Board of Governors of the Federal Reserve System

International Finance Discussion Papers

Number 620

August 1998

WHAT DETERMINES PUBLIC SUPPORT FOR AFFIRMATIVE ACTION?

\author{
Murat F. Iyigun and Andrew T. Levin
}

NOTE: International Finance Discussion Papers are preliminary materials circulated to stimulate discussion and critical comment. References in publications to International Finance Discussion Papers (other than an acknowledgment that the writer has had acccess to unpublished material) should be cleared with the author or authors. Recent IFDPs are available on the Web at www.bog.frb.fed.us. 


\title{
WHAT DETERMINES PUBLIC SUPPORT FOR AFFIRMATIVE ACTION?
}

\author{
Murat F. Iyigun and Andrew T. Levin*
}

\begin{abstract}
We present a public higher education finance model in which demand for educational services can exceed supply because of indivisibilities in educational investment. In such situations, a screening mechanism-which may be imperfect due to direct or indirect discrimination-is required for allocation. We show how changes in the education premium affect political support for affirmative action policies. When the education premium is relatively low, the matching efficiency gains provided by affirmative action policies are relatively high compared to the opportunity cost of not acquiring education, and the majority supports broader affirmative action. In contrast, when the education premium is high, the opportunity cost of not getting educated is high relative to the matching efficiency gains provided by affirmative action policies, and the majority's support for affirmative action is weaker. With endogenous wages, the negative relationship between the returns to education and affirmative action is reinforced.
\end{abstract}

keywords: Public Education, Education Premium, Affirmative Action, Screening.

* The authors are economists in the Division of International Finance, Board of Governors of the Federal Reserve System. The views in this paper are solely the responsibility of the authors and should not be interpreted as reflecting the views of the Board of Governors of the Federal Reserve System or of any other person associated with the Federal Reserve System. Please send all correspondence to: The Board of Governors of the Federal Reserve System, Mail Stop 23, Washington, D.C. 20551. 


\section{Introduction}

Since coming into effect in the 1960 s, affirmative action policies ${ }^{1}$ have remained controversial and important tools used to combat differences in earnings, employment and access to education. ${ }^{2}$ Throughout the 1970s and early 1980s, such policies received relatively wide and bi-partisan support. In the 1990s, however, opposition to affirmative action has gained momentum. For example, in 1995, a ruling by the U.S. Court of Appeals for the Fifth Circuit barred public colleges in Texas from considering the race of prospective students. And in 1996, the University of California dropped affirmative action in admissions as a result of the 1996 ballot initiative known as Proposition 209, which barred the consideration of race, ethnicity or gender in admissions to public colleges and universities in California. Why did such changes in public opinion and policy occur? More specifically, what are the economic factors that might help explain changes in political support for affirmative action?

In this paper, we present a model in which demand for education can exceed supply because of indivisibilities in educational investment ${ }^{3}$ and in which there are positive externalities of admitting applicants to public schools according to their ability. Thus, a screening mechanism, which may potentially be biased against minorities, is required to choose the student body. For a given amount of spending on public education, policies aimed at reducing screening biases have two effects in such a setup: First, they reduce

\footnotetext{
${ }^{1}$ The Civil Rights Act, which prohibits discrimination on the basis of race, gender or ethnicity, was enacted in 1964. Executive orders 11246 and 11375, which set the currently applicable standards of affirmative action policies in federal procurement, employment and education, were respectively signed in 1965 and 1967. In 1978, the Supreme Court ruled in the Bakke vs. the University of California case that the rigid rules dictated by admissions quotas violated Title VI of the Civil Rights Act but that race, gender or ethnicity lawfully could be considered as one of the admissions criteria.

${ }^{2}$ While some of the differences in access to education are due to direct discrimination, others are more subtle and indirect. For example, in the United States, it is often argued that SAT test scores are biased based on gender and race. Moreover, some argue that college-prep courses enhance SAT performance by providing useful test-taking strategies and that these courses do not augment human capital in any other way. Similarly, "private guidance counselors" help high school seniors improve their admission odds by supporting them in strenghtening other aspects of their applications. As these examples suggest, it is often argued that screening biases in some-if not most-cases are related to socio-economic disadvantages that minority households face. Regardless of their source though, it is well-documented that screening biases lead to lower intergenerational economic mobility [See, for example, Iyigun (forthcoming)], and-given that they exclude relatively able individuals who come from disadvantaged households from receiving education-to aggregate inefficiencies.

${ }^{3}$ This approach is similar in spirit to the one first proposed by Galor and Zeira (1993).
} 
the odds of admission to a public school of applicants from majority households. Second, such policies raise the stock of educated labor because more able minority applicants gain admission to public schools at the expense of less able applicants. Due to these effects, changes in the returns to education affect political support for affirmative action policies. In periods in which the education premium is relatively low, the matching efficiency gains provided by affirmative action are relatively high compared to the opportunity cost of not acquiring education, and the majority supports broader affirmative action. In contrast, in periods in which the returns to education is high, the majority's support for affirmative action declines as the opportunity cost of not getting educated increases relative to the matching efficiency gains provided by affirmative action policies.

Indeed, historical trends in the U.S. skill premia are consistent with the view that political support for affirmative action and the returns to education are inversely related: After rising in the 1960s, the education premium declined significantly over the next decade. During the 1980s and the early 1990s, however, the returns to education soared so that by 1994 it stood roughly 35 percent above its value in 1963. Moreover, between the late 1970s and mid-1980s when the return to education, experience and other components of unobservable skill were rising, the increase in the education premium outpaced the increase in the returns to experience and other components of skill. ${ }^{4}$

[Figure 1 about here.]

It is important to note at the outset that, although we identify returns to education as an important determinant of affirmative action policies, we do not claim economic factors alone-without reliance on sociological or cultural ones-can explain changes in the support for affirmative action. For example, one could argue that biases in screening for education and employment have been significantly reduced in the last three decades due to the Civil Rights Act, and therefore, that scaling back affirmative action policies is warranted. In fact, as the model below will show, the efficiency rationale for affirmative action policies depends on the existence and magnitude of screening biases. We do not

\footnotetext{
${ }^{4}$ See Juhn et al. (1993) and Murphy (1996).
} 
take a position on this or any other similar argument. Rather, our sole intent is to explore what- if any-are the effects of economic factors on the determination and scope of affirmative action. ${ }^{5}$

The remainder of the paper is organized as follows: In section 2, we review the relevant literature. In section 3, we define the economy and the admission process. In section 4, we discuss the equilibrium amount of resources devoted to public education and the optimal affirmative action policy rule supported by the majority. In section 5 , we discuss-in more detail-the stylized facts. In section 6 , we endogenize the education premium and show how its interplay with affirmative action policies reinforce the negative relationship between public support for affirmative action and the returns to education. And, in section 7 we conclude.

\section{Related Literature}

By design, this paper brings together the existing literature on public education with that on affirmative action. In two papers, Fernandez and Gali (1997) and Fernandez (1998) explore the role borrowing constraints play in the performance of exams versus markets as allocative mechanisms. In a model in which agents who differ in their initial wealth and ability are assigned to various investment opportunities or various quality schools, they show that exams dominate markets in terms of aggregate output. For sufficiently powerful (less biased) exam technologies, exams are superior to markets in terms of aggregate consumption as well. Glomm and Ravikumar (1992) compare the income distribution and growth implications of public versus private education. Their model is one in which all agents in the economy demand educational services to varying degrees and the quality of educational services depend on the total resources allocated to education. They find that private education, which will be chosen by higher income

\footnotetext{
${ }^{5}$ We should also make clear that the sole focus of this paper is affirmative action in higher education. Nonetheless, it would be straightforward to extend this model to include affirmative action in employment. As it will become more apparent below, equilibrium affirmative action policies in education and employment should be perfectly correllated when such policies in education are based on the votes of a majority who take into account the private costs and benefits of affirmative action. In that context, the full benefits of affirmative action in education cannot accrue with continued biases in the labor market.
} 
individuals, results in less subsequent mobility but higher growth rates. In contrast public education, which will be preferred by lower income groups, leads to greater social mobility at the expense of long-run economic growth. As a result, to the extent that the median voter is poorer than the mean income voter, public education is chosen in a more unequal society. Gradstein and Justman (1997) focus on why in a more democratic society that is unequal public education should be more likely to be chosen over private. They demonstrate that, because rational voters internalize all possible positive externalities of an education system, they do not necessarily choose one with more redistribution-public education in particular-over others that lead to higher long-run economic growth.

There are relatively fewer theoretical studies on affirmative action. Coate and Loury (1993a, 1993b) develop models in which employers who harbor negative stereotypes against certain groups are likely to assign workers belonging to those groups to less rewarding jobs. They show that, since this lowers the expected return for these workers on investments which make these workers more productive in more rewarding jobs, employers' negative beliefs can be confirmed in equilibrium even when all groups are ex ante identical. Welch (1976) examines employment quotas in a setup in which there is discrimination by employers. He shows how such quotas may create a shortage of skilled minority workers. Therefore, he argues, such quotas may lead unskilled minority workers to be assigned to skilled jobs as a result of firms' attempts to acquire the option of hiring additional skilled majority workers. Lundberg (1991) analyzes the problem of enforcing equal opportunity laws when the regulators' have imperfect information on employer personnel policies and on the relationship between worker characteristics and their productivities. She examines the social costs and benefits of two alternative regulatory regimes, one prohibiting the use proxies for race, sex or gender in the determination of worker wages, and the other requiring wages to depend on observed worker characteristics in the same way for each group.

Finally, in setting up the model below, we borrow heavily from the theoretical framework we first developed in Iyigun and Levin (1998). In that paper, we explore the role biases in screening play in determining the share of resources devoted to public education. We show that, while lower screening biases lead to a better allocation of a 
given amount of spending on education, they do not necessarily lead to more political support for public higher education, and thereby to higher aggregate human capital and output.

\section{The Economy and the Admissions Process}

We consider an economy in which there is a single consumption good and a continuum of parents of measure one. Parents live for two periods, and they get utility-without discounting-from their own consumption and from the expected consumption of their offspring. There is no population growth and each parent has one offspring who lives for one period. ${ }^{6}$

In the first period of life, parents consume. They also vote on the share of resources to be devoted to public higher education and on the degree of affirmative action policies to adopt in the following period. In the second period, they send their offspring to a public school if they are admitted. There is no borrowing. We assume that parent $i$ 's utility from her own consumption in period one and from her offspring's consumption in period two has a log-linear form:

$$
u_{i}=\lambda \ln \left(c_{i, 1}\right)+(1-\lambda) E\left[\ln \left(c_{i, 2}\right)\right],
$$

where $0<\lambda<1$, and where $c_{i, 1}$ and $c_{i, 2}$ respectively denote parent $i$ 's consumption in period one and the consumption of $i$ 's offspring in period two.

The ability endowments of the offspring are log-normally distributed, with $a_{i} \equiv$ $\log A_{i} \sim N(0,1)$. Given that the higher education system is public and that parents do not know their offspring's abilities when voting, the following constraints apply to maximizing (1):

\footnotetext{
${ }^{6}$ This assumption is clearly non-essential. Whether the offspring live for one period or two periods is irrelevant since, in this context, we do not focus on the dynamics of public education finance and affirmative action.
} 


$$
\begin{gathered}
c_{i, 1} \leq\left(1-\tau_{i}^{*}\right) y_{i} \\
E\left[\ln \left(c_{i, 2}\right)\right]={ }_{0} \int^{a_{i}^{*}} \ln \left[B(E) w^{u}\right] \phi(a) d a+a_{i}^{*} \int^{\infty} \ln \left[B(E) w^{e}\right] \phi(a) d a \\
=\ln B(E)+\Phi\left(a_{i}^{*}\right) \ln \left(w^{u}\right)+\left[1-\Phi\left(a_{i}^{*}\right)\right] \ln \left(w^{e}\right),
\end{gathered}
$$

where $\phi($.$) and \Phi($.$) respectively denote the probability density function (p.d.f.) and$ the cumulative distribution function (c.d.f.) of the log of innate abilities, $y_{i}$ represents individual $i$ 's initial endowment, $\tau_{i}^{*}$ represents her preferred tax rate, $a_{i}^{*}$ the log of the minimum ability level of $i$ 's offspring required for admission to a public school, and where $w^{e}, w^{u}$ respectively denote the wage rates paid to educated and uneducated labor. Note that the level of technology in this economy, $B$, depends on the aggregate efficiency units of educated labor, $E$. We assume that $B$ satisfies the standard Inada conditions: That is, $B^{\prime}(E)>0, B^{\prime \prime}(E)<0, \lim _{E \rightarrow 0} \partial B(E) / \partial E=\infty$ and $\lim _{E \rightarrow \infty} \partial B(E) / \partial E=0$.

\section{Optimal Tax Rates and Affirmative Action}

Let $c, c>0$, denote the cost of education per pupil, and $y$ denote aggregate wealth in period one. Then, the supply of educational services in the second period, $S$, will be given by

$$
S=\frac{\tau^{*} y}{c}
$$

where $\tau^{*}$ represents the equilibrium tax rate.

We assume that when the supply of public education, $S$, is less than its demand, ${ }^{7}$ applicants are admitted to schools based on their measurable productive abilities. ${ }^{8}$ To make the problem interesting, however, we also assume that the proxy for measuring

\footnotetext{
${ }^{7}$ Note that, in our simple framework, the demand for education equals one as the second period wage earnings of educated labor is higher than that of uneducated labor for all ability levels.

${ }^{8}$ For sake of simplicity, we abstract from any cost associated with screening.
} 
individuals' productive abilities is imperfect. In particular, we consider the proxy to be biased against a group of families. ${ }^{9}$ Let $I_{i}, I_{i}: R^{2} \rightarrow R$, denote the log of the ability of parent $i$ 's offspring as measured with the available proxy. Then,

$$
I^{i}= \begin{cases}a_{i} & \text { with probability } p \\ a_{i}-\beta+O^{*} & \text { with probability } 1-p\end{cases}
$$

where $\beta, \beta \geq 0$, denotes the negative biases inherent in screening, and $O^{*}, O^{*} \geq 0$, denotes the amount of these biases offset (in equilbrium) by affirmative action policies. ${ }^{10}$ As (4) indicates, $1-p$ fraction of the parents (and their offspring) are subject to negative testing biases. For the remainder of the analysis, we assume that these biases apply to a segment of the population-henceforth the minority-who does not possess enough votes to influence the outcome of the political process. That is we assume that $p>d$ where $d$ denotes the decisive fraction of votes needed to enact a legislation.

Let $I^{*}$ denote the threshold score required for admission to a public school. If the measured ability level of parent $i$ 's offspring is greater than or equal to the threshold level, $I^{*}$, then $i$ 's offspring is admitted to a public school and she earns $a_{i} B(e) w^{e}$ in the second period. Otherwise, she remains uneducated and earns $a_{i} B(E) w^{u}$. Let $a_{p}^{*}$ and $a_{1-p}^{*}$ respectively denote the relevant thresholds of admission for the children of the majority and the minority that are consistent with $I^{*}$. Equation (4) implies that, when no affirmative action policies are in effect, $a_{p}^{*}=I^{*}<a_{1-p}^{*}=I^{*}+\beta$. That is the threshold ability necessary to gain admission for children of the majority is strictly less than that of the children of the minority. Otherwise, $a_{p}^{*}=I^{*}$ and $a_{1-p}^{*}=I^{*}+\beta-O^{*}$. In any case, $I^{*}$ satisfies the following:

\footnotetext{
${ }^{9}$ Although we do not specify which parental characteristics are important in generating unfavorable biases in screening for higher education admissions, as we have noted in the introduction, most of these are socio-economic in nature. There are also on-going debates on whether standardized tests favor members of certain gender, race or ethnicity.

${ }^{10}$ In our view, a more comprehensive version of (4) ought to include a measurement error term. Although, for simplicity, we abstract from it in the version provided here, we show in the appendix that the qualitative nature of our results are robust to such a modification.
} 


$$
S=1-\Psi\left(I^{*}\right)
$$

where $\Psi\left(I^{*}\right)$ denotes the population c.d.f.

In deciding on the optimal share of resources devoted to higher public education and the affirmative action rule, parents maximize (1) with respect to the tax rate, $\tau$, and the amount of biases offset by affirmative action, $O$. It is straightforward to show that the majority, $p$, of parents prefer a tax rate, $\tau^{*}$, which satisifies the following first-order condition:

$$
\frac{\partial u_{p}}{\partial I^{*}}=-\frac{\lambda}{1-\tau^{*}} \frac{\partial \tau^{*}}{\partial I^{*}}-(1-\lambda) \ln \left(\frac{w^{e}}{w^{u}}\right) \phi\left(a_{p}^{*}\right)+(1-\lambda) \frac{B^{\prime}(E)}{B(E)} \frac{\partial E}{\partial I^{*}}=0
$$

where

$$
\begin{aligned}
& \frac{\partial \tau^{*}}{\partial I^{*}}=-\frac{c}{y} \psi\left(I^{*}\right)=-\frac{c}{y}\left[p \phi\left(I^{*}\right)+(1-p) \phi\left(I^{*}+\beta-O^{*}\right)\right]<0, \\
& E=p_{I^{*}} \int^{\infty} \exp (a) \phi(a) d a+(1-p)_{I^{*}+\beta-O^{*}} \int^{\infty} \exp (a) \phi(a) d a
\end{aligned}
$$

and where

$$
\frac{\partial E}{\partial I^{*}}=-\left[p \exp \left(I^{*}\right) \phi\left(I^{*}\right)+(1-p) \exp \left(I^{*}+\beta-O^{*}\right) \phi\left(I^{*}+\beta-O^{*}\right)\right]<0
$$

The first term in (6) denotes the marginal cost of lowering the admissions threshold and the second and third terms represent its marginal benefit. Note that, while the first benefit depends on the education premium, $w^{e} / w^{u}$, and accrues only when the offspring gains admission to a public school, the second benefit arises because of the positive global externality provided by having a more educated labor force. Moreover, the first benefit 
of raising the supply of higher public education depends positively on the p.d.f. of the ability of parent $i$ 's offspring at that threshold, $\phi\left(a_{i}^{*}\right)$, but the cost of raising supply is related to the p.d.f. of abilities for the whole population. In (7), that latter term is given by the mixture density function $\psi\left(I^{*}\right), \psi\left(I^{*}\right)=p \phi\left(I^{*}\right)+(1-p) \phi\left(I^{*}+\beta-O^{*}\right)$. Put differently, the first-as well as the net-marginal benefit of lowering the admissions threshold, $I^{*}$, depend positively on the probability density of the ability of parent $i$ 's offspring relative to that of the population at that threshold. When the ratio of the voter's offspring density to population density is small, the net marginal benefit is low as most of the benefits of lowering the admissions threshold accrue to the children of other groups. Equation (8) implies that when affirmative action policies do not fully offset negative biases in screening (i.e. $\beta-O^{*}>0$ ), educated workers come disproportionately from majority households. (9) indicates that the aggregate efficiency units of educated labor, $E$, depends negatively on the cutoff score, $I^{*}$.

Figures 2 and 3 show the log-ability densities for the children of the two groups, $\phi($.$) , as well as the mixture p.d.f. for the whole population, \psi($.$) . Figure 2$ depicts for $\beta=3$ the case when there is no affirmative action. Note how, at relatively high cutoff levels of the threshold indicator, $I_{i}$, the mixture density function, $\psi($.$) , lies below the$ density function of log-abilities for the offspring of the majority voters. In contrast, at lower threshold levels, the density of log-abilities for offspring of those parents are below that of the population. Figure 3 shows the same variables for $\beta=3$ with partial offset from affirmative action. With affirmative action policies in effect, the ratio of the majority's offspring density to population density is smaller, which reflects the increase in the odds of admission to public schools of the children of the minority at the expense of those of the majority.

[Figures 2 and 3 about here.]

Note that in the limiting case where $\beta \rightarrow 0$, the ratio of the densities approach one. In that case neither screening biases, $\beta$, nor the fraction of the minority voters, $1-p$, has an influence on the equilibrium share of resources devoted to public education supply. 
In order to further highlight the role that screening biases play in the majority's choice of the share of resources devoted to public higher education, let us briefly focus on a case in which there are no positive externalities on the level of technology, $B$, of the aggerate efficiency units of educated labor, $E$. In that case, the share of resources devoted to public education supply is higher when there are biases in screening. More formally, let $G=\partial u_{p} / \partial I^{*}=0$. Using the implicit function theorem it is straightforward to show that

$$
\frac{\partial \tau^{*}}{\partial \beta}=-\frac{G_{\beta}}{G_{\tau^{*}}}=-\frac{p \phi\left(I^{*}+\beta\right)}{G_{\tau^{*}}} \frac{\lambda}{1-\tau^{*}} \frac{c}{y}\left[2\left(I^{*}+\beta\right)+\frac{1}{1-\tau^{*}} \frac{c}{y} \psi\left(I^{*}\right)\right] .
$$

By assumption, $\tau^{*}$ is an interior solution to the maximization problem of a majority parent, and as a result, $G_{\tau^{*}}$ is strictly negative. The term in brackets show the two effects of higher biases in screening: $2\left(I^{*}+\beta\right)$ represents how, at the threshold $I^{*}$, a given supply of educational services benefit the majority voters. This effect arises because screening biases shift down the relative position of the minority applicants in the $I_{i}$ map, and raise the majority voters' odds of admission when $I^{*}+\beta>0$. Note that a sufficient but not necessary condition for this effect to be positive is that resources allocated to public education is restrictive enough that the threshold score, $I^{*}$, is non-negative. The second term in brackets in equation (10), $\frac{1}{1-\tau^{*}} \frac{c}{y} \psi\left(I^{*}\right)$, represents the effect on utility of a lower fraction of children born to minority voters qualifying for admission at a given threshold, $I^{*}$. This effect arises because when biases are larger, fewer resources need to be devoted to public education supply as a lower fraction of minority parents' offspring qualify for admission to schools. Clearly, this effect is unconditionally positive. The marginal utility and disutility of taxes, when there are no positive externalities of educated labor, are depicted in Figure 4. As is consistent with the above analysis, the utility of resources devoted to public education for majority voters peaks at lower threshold levels and higher tax rates when screening biases are larger.

[Figure 4 about here.] 
Note that (10) also implies that the effect of screening biases, $\beta$, on the equilibirum share of resources devoted to public education, $\tau^{*}$, approaches zero as biases approach infinity. Namely that

$$
\lim _{\beta \rightarrow \infty}\left(\frac{\partial \tau^{*}}{\partial \beta}\right)=0 .
$$

Turning once again to the general case in which externalities exist and $O^{*} \geq 0$, the optimal affirmative action rule chosen by the majority of parents, $O^{*}$, satisfies the following first-order condition

$$
\frac{\partial u_{p}}{\partial O^{*}}=(1-\lambda) \frac{B^{\prime}(E)}{B(E)} \frac{\partial E}{\partial O^{*}}-\frac{\lambda}{1-\tau^{*}} \frac{\partial \tau^{*}}{\partial O^{*}} \leq 0
$$

where

$$
\frac{\partial E}{\partial O^{*}}=(1-p) \exp \left(I^{*}+\beta-O^{*}\right) \phi\left(I^{*}+\beta-O^{*}\right)>0, \quad \text { for } O^{*}<\beta
$$

and where

$$
\frac{\partial \tau^{*}}{\partial O^{*}}=\frac{c}{y} \psi\left(I^{*}\right)=\frac{c}{y}(1-p) \phi\left(I^{*}+\beta-O^{*}\right)>0
$$

The first term in (12) represents the marginal benefit of eliminating negative screening biases. As (13) shows, for a given amount of spending on educational services, a higher $O^{*}$ raises the aggregate efficiency units of educated labor provided that $O^{*}<\beta$. The obvious reason is that, for a given supply of educational services, affirmative action policies improve mathcing efficiency in that they allow more able minority applicants to gain admission instead of relatively less able majority individuals. The second term in (12) is the marginal cost of affirmative action. As (14) indicates, for a given cutoff score, $I^{*}$, affirmative action policies lead to a larger number of applicants qualifying for 
admission. Thus, offsetting biases in screening with affirmative action policies requires higher educational spending, and therefore higher tax rates.

Note that, in this model, affirmative action is meaningful only if resources are allocated to public education in equilibrium. Moreover, it is straightforward to establish that when the education premium approaches zero (i.e. $w^{e} / w^{u} \rightarrow 1$ ), it is in the interest of the majority voters to support full affirmative action, where $O^{*}=\beta$. In contrast, when the education premium is positive so that $w^{e} / w^{u}>1$, and an interior solution exists with a positive amount of resources devoted to education and to affirmative action policies, ${ }^{11}$ we can show that $O^{*}<\beta .{ }^{12}$ In that case, combining (6) and (12) we get

$$
p \phi\left(I^{*}\right) \frac{B^{\prime}(E)}{B(E)}\left\{\exp \left(I^{*}+\beta-O^{*}\right)-\exp \left(I^{*}\right)\right\}=\ln \left(\frac{w^{e}}{w^{u}}\right) .
$$

The term on the lhs of (15) shows the net marginal benefit of affirmative action, while that on the rhs shows the net marginal benefit of raising the supply of educational services. The former accrues through the positive social externality-which in our model is through an improvement in the level of the technology, and the latter only through gaining admission to a public school. Thus, when there is an increase in the education premium, $w^{e} / w^{u}$, the net marginal benefit of majority voters' children being admitted to a public school increases relative to that of affirmative action, and the equilibrium amount of the affirmative action rule, $O^{*}$, declines. That is, $\partial O^{*} / \partial\left(w^{e} / w^{u}\right)<0$ for most plausible parameter values [For proof, see appendix section 8.2.]

\footnotetext{
${ }^{11}$ Note that, since we utilize the standard neoclassical assumptions about how the level of technology, $B$, depends on educated labor, $E$, there exists one pair of an interior solution tax rate, $\tau^{*}>0$, and an affirmative action rule, $O^{*} \geq 0$, that satisfies equations (6)-(9) and (12)-(14).

${ }^{12}$ This raises a contentious issue as some argue that currently applicable affirmative action rules more than compensate minorities for biases in screening (i.e. $O^{*}>\beta$ ). In our static setup, it is not possible to generate such affirmative action rules. However, a dynamic version of the model in which there is dynastic (family-specific) human capital accumulation can generate optimal rules with $O^{*}>\beta$. Under that setup, the efficient allocation rule would dictate that-ceteris paribus-applicants with higher marginal product of human capital (i.e. those with lower parental human capital) should be admitted to public schools. The qualitative nature of the results presented here would remain unchanged in that version, although the analytics will get significantly more complicated.
} 


\section{Stylized Facts}

Opposition to affirmative action policies in education stood at a much higher level in the mid-1990s compared to the early 1980s-the earliest period for which opinion polls exist, as far as we know. In 1982, 63 percent of the representative sub-sample of the U.S. adult population responded that they would be more likely to vote for a presidential candidate who favored affirmative action in education and employment for women and minorities. In contrast, only 55 percent of the respondents to a national poll in 1995 said that they generally favored affirmative action programs. At least as striking, 86 percent of those surveyed in 1995 thought that affirmative action programs for women and minorities were needed when they were first adopted in the late 1960s. There seems to be some evidence that the decline in public support for affirmative action was especially rapid in the early 1990s: In 1992, 26 percent responded that they would less likely vote for a candidate who favored strengthening affirmative action laws. Two and a half years later, 43 percent said that they opposed strengthening affimative action policies. (Gallup, 1982, 1992, 1994, 1995). ${ }^{13}$

As we have stated in our introduction, recent court rulings in Texas and legislation in California have abolished affirmative action in education. In 1995, the U.S. Court of Appeals for the Fifth Circuit barred public colleges in Texas from considering race as an admission criterion. In 1996, the University of California eliminated affirmative action in admissions because of the passage of the ballot initiative known as Proposition 209. Accordingly, race, ethnicity or gender can no longer be considered for admitting prospective students to public colleges and universities in California.

There exists a large body of work which documents the historical pattern of the education premium in the United States. Among those, Juhn, Murphy and Pierce (1993) and Murphy (1996) show that, after rising in the 1960s, the education premium declined significantly over the next decade. Starting in the early 1980s, however, the returns to education rose very rapidly. By 1994 it stood roughly 35 percent above its value in 1963. Somewhat similarly, Autor, Katz and Krueger (1997) calculate that college graduates, who earned 55 percent more than high school graduates in the 1970s, had 41 and 62

\footnotetext{
${ }^{13}$ For more detail on these and some other related Gallup polls, see appendix section 8.4.
} 
percent higher earnings than high school graduates respectively in the 1980s and 1990s.

\section{Endogenous Wages}

In what follows we endogenize the education premium and show how its interplay with affirmative action policies reinforce the negative relationship between public support for affirmative action and the returns to education. Although we do not extend the model to capture the dynamic interaction between these variables, in this section we demonstrate-rather informally-how wider support for affirmative action deflates the education premium by making college admissions more efficient. As we have shown above, lower returns to education would strengthen further the public support for affirmative action. Conversely, if support for affirmative action weakens due to an exogenous rise in the education premium, we show below that greater inefficiency in admissions caused by more restrictive affirmative action would lead returns to education in subsequent periods to rise above and beyond what would be implied by the initial shock.

Let the second period aggregate output, $y_{2}$, be given by a CES production function:

$$
y_{2}=B(E)\left[\alpha E^{\rho}+(1-\alpha) U^{\rho}\right]^{\frac{1}{\rho}}, \quad 0<\alpha<1
$$

where $E$ and $U$ respectively denote the efficiency units of educated and uneducated labor input, and where $\rho,-\infty \leq \rho \leq 1$, denotes the elasticity of substitution. Using the notation in the preceding sections, the efficiency units of educated and uneducated labor input will be given by the following:

$$
E=p_{I^{*}} \int^{\infty} \exp (a) \phi(a) d a+(1-p)_{I^{*}+\beta-O^{*}} \int^{\infty} \exp (a) \phi(a) d a
$$

and,

$$
U=p_{-\infty} \int^{I^{*}} \exp (a) \phi(a) d a+(1-p)_{-\infty} \int^{I^{*}+\beta-O^{*}} \exp (a) \phi(a) d a
$$

We assume that labor markets are competitive and that both types of labor are 
paid their marginal products. Namely,

$$
w^{e}=\alpha E^{\rho-1} B(E)\left[\alpha E^{\rho}+(1-\alpha) U^{\rho}\right]^{\frac{1-\rho}{\rho}},
$$

and,

$$
w^{u}=(1-\alpha) U^{\rho-1} B(E)\left[\alpha E^{\rho}+(1-\alpha) U^{\rho}\right]^{\frac{1-\rho}{\rho}},
$$

where $w^{e}$ and $w^{u}$ respectively denote the wage rates per efficiency units of labor supplied by educated and uneducated workers.

Taken together, equations (17)-(20) demonstrate how-ceteris paribus-higher degrees of screening biases against the minority lower the efficiency units of educated labor and raise the education premium (by leading to an increase in the wage rate paid to educated labor, $w^{e}$, and an associated decline in that paid to uneducated labor, $w^{u}$ ). More formally, we can show that

$$
\frac{\partial w^{e}}{\partial \beta}=(\rho-1) B(E) w^{e} \frac{(1-\alpha) U^{\rho-1}}{E\left[\alpha E^{\rho}+(1-\alpha) U^{\rho}\right]} \frac{\partial E}{\partial \beta}
$$

and that

$$
\frac{\partial w^{u}}{\partial \beta}=(\rho-1) B(E) w^{u} \frac{\alpha E^{\rho-1}}{U\left[\alpha E^{\rho}+(1-\alpha) U^{\rho}\right]} \frac{\partial U}{\partial \beta}
$$

where

$$
\frac{\partial E}{\partial \beta}=-\frac{\partial U}{\partial \beta}=-\frac{(1-p) \phi\left(I^{*}+\beta-O^{*}\right)}{1+\frac{1-p}{p} \frac{\phi\left(I^{*}+\beta-O^{*}\right)}{\phi\left(I^{*}\right)}}\left\{\exp \left(I^{*}+\beta-O^{*}\right)-\exp \left(I^{*}\right)\right\}
$$

whith $\frac{\partial w^{e}}{\partial \beta}>0$ and $\frac{\partial w^{u}}{\partial \beta}<0$ for $\rho<1$ and $\beta>0$.

When wages are determined endogenously, voters take into account not only how increases in the share of resources devoted to public education change the odds of admission for their offspring but also how such increases alter the education premium. Rewriting equation (6) to capture this change, we get 


$$
\begin{aligned}
\frac{\partial u_{p}}{\partial I^{*}}=-\frac{\lambda}{1-\tau^{*}} \frac{\partial \tau^{*}}{\partial I^{*}} & -(1-\lambda) \ln \left(\frac{w^{e}}{w^{u}}\right) \phi\left(I^{*}\right) \\
& +(1-\lambda)\left[\frac{B^{\prime}(E)}{B(E)} \frac{\partial E}{\partial I^{*}}+\frac{\Phi\left(I^{*}\right)}{w^{u}} \frac{\partial w^{u}}{\partial I^{*}}+\frac{1-\Phi\left(I^{*}\right)}{w^{e}} \frac{\partial w^{e}}{\partial I^{*}}\right]=0
\end{aligned}
$$

where $\frac{\partial E}{\partial I^{*}}$ is given by (9) and where

$$
\frac{\Phi\left(I^{*}\right)}{w^{u}} \frac{\partial w^{u}}{\partial I^{*}}+\frac{1-\Phi\left(I^{*}\right)}{w^{e}} \frac{\partial w^{e}}{\partial I^{*}}=(\rho-1) \frac{E+U}{\left[\alpha E^{\rho}+(1-\alpha) U^{\rho}\right]}\left[\begin{array}{c}
\frac{1-\Phi\left(I^{*}\right)}{E}(1-\alpha) U^{\rho-1} \\
- \\
\frac{\Phi\left(I^{*}\right)}{U} \alpha E^{\rho-1}
\end{array}\right] \frac{\partial E}{\partial I^{*}} .
$$

The last term in (24) shows the effects of changing the share of resources devoted to public education on the expected wage income. Under reasonable parameter restrictions, it is relatively easy to establish-as we do in the appendix-that this term is strictly negative for $\forall \rho<1$ when, $\forall I^{*} \in[-\infty,+\infty],(E+U) / U \geq 1 / \Psi\left(I^{*}\right)$. That is, when the cost of education, $c$, is strictly positive or when parents put some positive weight on utility from their own consumption in period one, $\lambda>0$, the equilibrium share of resources devoted to public education supply is always less than that amount which would maximize second period output, $y_{2}$. Thus, when wage rates are endogenously determined, negative biases against the minority have an additional impact on the share of resources devoted to public education finance. This directly follows from the fact that-ceteris paribus, screening distortions inflate the education premium by leading to more inefficient admissions. Consequently, with such admission biases (i.e. higher $\beta$ ), aggregate units of educated labor input, $E$, declines and that of uneducated labor input, $U$, rises, thereby leading to an increase in the value of (25).

When wage rates are endogenous, the optimal affirmative action rule chosen by the majority will be given by 


$$
\frac{\partial u_{p}}{\partial O^{*}}=(1-\lambda)\left[\frac{B^{\prime}(E)}{B(E)} \frac{\partial E}{\partial O^{*}}+\frac{\Phi\left(I^{*}\right)}{w^{U}} \frac{\partial w^{u}}{\partial O^{*}}+\frac{1-\Phi\left(I^{*}\right)}{w^{E}} \frac{\partial w^{e}}{\partial O^{*}}\right]-\frac{\lambda}{1-\tau^{*}} \frac{\partial \tau^{*}}{\partial O^{*}} \leq 0
$$

with $\frac{\partial E}{\partial O^{*}}$ and $\frac{\partial \tau^{*}}{\partial O^{*}}$ still given by (13) and (14).

The first term in (26) represents the marginal benefit of eliminating the negative biases in screening, and the second term, its cost. As was previously the case, affirmative action is meaningful only if resources are allocated to public education in equilibrium. Moreover, when the education premium approaches zero (i.e. $w^{e} / w^{u} \rightarrow 1$ ), it is in the interest of the majority voters to support full affirmative action, where $O^{*}=\beta$. In contrast, when the education premium is positive so that $w^{e} / w^{u}>1$, an interior solution exists with a positive amount of resources devoted to education and to affirmative action policies, with $O^{*}<\beta$. In that case, combining (24) and (26) we get

$$
p \phi\left(I^{*}\right) \Lambda\left\{\exp \left(I^{*}+\beta-O^{*}\right)-\exp \left(I^{*}\right)\right\}-(\rho-1) \ln \left(\frac{E}{U}\right)=\ln \left(\frac{\alpha}{1-\alpha}\right)
$$

where

$$
\Lambda=\left\{\begin{array}{c}
\frac{B^{\prime}(E)}{B(E)} \\
+ \\
(\rho-1) \frac{E+U}{\left[\alpha E^{\rho}+(1-\alpha) U^{\rho}\right]}\left[\frac{1-\Phi\left(I^{*}\right)}{E}(1-\alpha) U^{\rho-1}-\frac{\Phi\left(I^{*}\right)}{U} \alpha E^{\rho-1}\right]
\end{array}\right\}>0 .
$$

Equation (27) is the analog of (15). The main difference is that, when wages are determined endogenously, increases in the supply of education (and, therefore in the amount of efficiency units of educated labor, $E$ ) improve the existing level of technology, $B$, and raise the expected wage income. The latter effect is captured by the second term in (28) which is strictly positive. As (27) clearly indicates, an exogenous increase in $\alpha$ will lead to an increase in the supply of educational services (i.e. to a reduction in 
$\left.I^{*}\right)$ and a decrease in the equilibrium affirmative action rule, $O^{*}$. Ceteris paribus, the partial effect of the latter is a drop in the efficiency units of educated labor, $E$, and a disproportionate rise in the education premium. Of course, the partial effect on the returns to education of an increase in resources devoted to public education is negative.

\section{Conclusion}

The model above relates political developments regarding affirmative action to changes in the returns to education. It argues that the pickup in opposition to affirmative action in the United States, as evidenced by recent court rulings in Texas and California, may be related to the rapid increase in the education premium in the 1980 s and early1990s.

In the model presented above, the demand for education exceeds supply because of indivisibilities in educational investment and there are positive social externalities of admitting applicants to public schools according to their ability. Therefore, a screening mechanism, which may potentially be biased against minorities, is required to choose the student body. In such a setup, we show how changes in the returns to education affect the support for affirmative action policies. In periods in which the education premium is relatively low, the matching efficiency gains provided by affirmative action are relatively high compared to the opportunity cost of not acquiring education, and the majority supports broader affirmative action. In contrast, in periods in which the returns to education is high, the majority's support for affirmative action declines as the opportunity cost of not getting educated increases relative to the matching efficiency gains provided by affirmative action policies. Moreover, endogenous wages reinforce the negative relationship between the returns to education and the public support for affirmative action. 


\section{Appendix}

8.1. When the proxy has measurement error:

We modify equation (4) to reflect family backgrounds biases as well as measurement errors.

$$
I^{i}= \begin{cases}a_{i}+\varepsilon_{i} & \text { with probability } p \\ a_{i}-\beta+\varepsilon_{i} & \text { with probability } 1-p\end{cases}
$$

where the error term, $\varepsilon_{i}$, is log-normally distributed, with $\varepsilon_{i} \sim N(0,1)$. Consequently, we also need to modify the offspring's expected income:

$$
E\left[\ln \left(c_{i, 2}\right)\right]=\ln \left(w^{u}\right)_{-\infty} \int^{\infty} \Phi\left(a_{i}^{*}\right) \phi(\varepsilon) d \varepsilon+\ln \left(w^{e}\right)_{-\infty} \int^{\infty}\left[1-\Phi\left(a_{i}^{*}\right)\right] \phi(\varepsilon) d \varepsilon,
$$

where $a_{i}^{*}=a_{p}^{*}=I^{*}+\beta-\varepsilon$ if the parent is influential and $a_{i}^{*}=a_{1-p}^{*}=I^{*}-\varepsilon$ if he is not.

Rewriting the first-order condition originally given by (6), we get

$$
\frac{\partial u_{p}}{\partial I^{*}}=-\frac{\lambda}{1-\tau^{*}} \frac{\partial \tau^{*}}{\partial I^{*}}-(1-\lambda) \ln \left(\frac{w^{e}}{w^{u}}\right)_{-\infty} \int^{\infty} \phi\left(I^{*}-\varepsilon\right) \phi(\varepsilon) d \varepsilon,
$$

where

$$
\frac{\partial \tau^{*}}{\partial I^{*}}=-\frac{c}{y}\left[p_{-\infty} \int^{\infty} \phi\left(I^{*}+\beta-\varepsilon\right) \phi(\varepsilon) d \varepsilon+(1-p)_{-\infty} \int^{\infty} \phi\left(I^{*}-\varepsilon\right) \phi(\varepsilon) d \varepsilon\right]
$$

Thus, equation (10) becomes

$$
\frac{\partial \tau^{*}}{\partial \beta}=-\frac{p}{G_{\tau^{*}}} \frac{\lambda}{1-\tau^{*}} \frac{c}{y}\left[\begin{array}{c}
2-\infty \int^{\infty}\left(I^{*}+\beta-\varepsilon\right) \phi\left(I^{*}+\beta-\varepsilon\right) \phi(\varepsilon) d \varepsilon \\
+ \\
\frac{-\infty \int^{\infty} \phi\left(I^{*}+\beta-\varepsilon\right) \phi(\varepsilon) d \varepsilon}{1-\tau^{*}} \frac{c}{y} \psi\left(I^{*}\right)
\end{array}\right]
$$


The interpretation of (A.5) is similar to that of (10): The first term in brackets represents how, at the threshold $I^{*}$, a given bias harms the minority. The exclusion effect of biases on the equilibrium tax rates is positive because screening biases shift the relative position of minority's offspring in the $I_{i}$ map and lower the threat of competition in admissions that they pose to the children of the majority. The second term in brackets represents the effect on utility of a smaller fraction of minority children qualifying for admission at a given threshold, $I^{*}$. The effect on equilibrium tax rates of less competition at a given threshold is always positire. Therefore, as in (10), $\frac{\partial \tau^{*}}{\partial \beta}$ is unambigiously positive when $I^{*}+\beta>0$.

The same modification would then apply to (12).

8.2. Proving that $\frac{\partial O^{*}}{\partial\left(\frac{w e}{w^{u}}\right)}<0$ :

Rearranging equation (15) and using the implicit function theorem, we get

$$
\frac{\partial O^{*}}{\partial\left(\frac{w e}{w^{u}}\right)}=-\frac{p \phi\left(I^{*}\right)\left\{\exp \left(I^{*}+\beta-O^{*}\right)-\exp \left(I^{*}\right)\right\} \frac{\partial I^{*}}{\partial\left(\frac{w e}{w^{u}}\right)}\left[\frac{B^{\prime \prime}(E)-B^{\prime}(E)^{2}}{B(E)^{2}} \frac{\partial E}{\partial I^{*}}+\frac{B^{\prime}(E)}{B(E)}\left(1-I^{*}\right)\right]-\frac{w^{u}}{w^{e}}}{p \phi\left(I^{*}\right)\left[\frac{B^{\prime \prime}(E)-B^{\prime}(E)^{2}}{B(E)^{2}} \frac{\partial E}{\partial O^{*}}-\frac{B^{\prime}(E)}{B(E)}\left(I^{*}+\beta-O^{*}\right) \exp \left(I^{*}+\beta-O^{*}\right)\right]}
$$

where $\frac{\partial I^{*}}{\partial\left(\frac{w e}{w^{u}}\right)}<0$, as implied by the first-order condition in (6), and where $\frac{\partial E}{\partial I^{*}}<0$ and $\frac{\partial E}{\partial O^{*}}>0$, as given respectively by (9) and (13). Assuming that the exponent of the equilibrium cutoff threshold ability level, $\exp \left(I^{*}\right)$, is within about two and a half standard deviations of the mean ability level (which implies that $1-I^{*}>0$ ), guarantees that $\partial O^{*} / \partial\left(\frac{w e}{w^{u}}\right)$ is strictly negative.

8.3. Proving that $\frac{B^{\prime}(E)}{B(E)} \frac{\partial E}{\partial I^{*}}+\frac{\Phi\left(I^{*}\right)}{w^{U}} \frac{\partial w^{u}}{\partial I^{*}}+\frac{1-\Phi\left(I^{*}\right)}{w^{E}} \frac{\partial w^{e}}{\partial I^{*}}$ is strictly negative when $\rho<1$ :

Given (9), $\frac{B^{\prime}(E)}{B(E)} \frac{\partial E}{\partial I^{*}}$ is unambigiously negative, but the sign of $\frac{\Phi\left(I^{*}\right)}{w^{U}} \frac{\partial w^{u}}{\partial I^{*}}+\frac{1-\Phi\left(I^{*}\right)}{w^{E}} \frac{\partial w^{e}}{\partial I^{*}}$, which is given by $(25)$, depends on the sign of $\frac{1-\Phi\left(I^{*}\right)}{E}(1-\alpha) U^{\rho-1}-\frac{\Phi\left(I^{*}\right)}{U} \alpha E^{\rho-1}$. 
For heuristic purposes, consider the case in the cost of education, $c$, or the weight of parents' consumption in utility, $\lambda$, equals zero. Then, the amounts of efficiency units of educated and uneducated labor that maximize second period aggregate output, $y_{2}$, are given by

$$
\left(\frac{U}{E}\right)=\left(\frac{\alpha}{1-\alpha}\right)^{\frac{1}{\rho-1}}
$$

Thus, when $c, \lambda>0$, the wage rate paid to educated labor, $w^{e}$, exceeds that paid to uneducated labor, $w^{u}$, and $(1-\alpha) U^{\rho-1}<\alpha E^{\rho-1}$. When, $\forall I^{*} \in[-\infty,+\infty]$, $(E+U) / U \geq 1 / \Psi\left(I^{*}\right)$, it follows that $\left[1-\Phi\left(I^{*}\right)\right] / E<\Phi\left(I^{*}\right) / U$, which completes the proof.

8.4. Some Gallup survey results on affirmative action ${ }^{14}$

- Question: (Would you be more likely or less likely to vote for a candidate who took the following positions or would it not affect your opinion either way?)...Favored affirmative-action plans that guarantee minorities and women access to education and jobs.

Responses:

More likely: $\quad 63 \%$

Less likely: $\quad 19 \%$

No effect: $\quad 14 \%$

Don't know: $\quad 4 \%$

Population: National Adult

Population Size: 1009

\footnotetext{
${ }^{14}$ The margin of error on all listed surveys is \pm 3 percent.
} 
Interview Method: Telephone

Survey Date: January-February 1982.

- Question: Do you generally favor or oppose affirmative-action programs for women and minorities?

Responses:

Favor: $\quad 55 \%$

Oppose: $\quad 34 \%$

No opinion: $\quad 11 \%$

Population: National Adult

Population Size: 1220

Interview Method: Telephone

Survey Date: March 1995.

- Question: When affirmative-action programs were first adopted almost thirty years ago, do you think they were needed to help women and racial minorities overcome discrimination, or were they not needed thirty years ago?

Responses:

Needed: $\quad 86 \%$

Not needed: $\quad 12 \%$

No opinion: $\quad 2 \%$

Population: National Adult

Population Size: 1003

Interview Method: Telephone

Survey Date: February 1995.

- Question: (As I read you each of the following issue positions, please tell me if you would be more likely or less likely to vote for a presidential candidate taking 
this position-or if it would not make much difference.)... What if the candidate favored...strengthening affirmative-action laws for women and minorities?

Responses:

More likely: $\quad 51 \%$

Less likely: $\quad 26 \%$

Not much difference: $\quad 18 \%$

Don't know/Refused: $\quad 5 \%$

Population: National Adult

Population Size: 1421

Interview Method: Telephone

Survey Date: January 1992.

- Question: Do you favor or oppose strengthening affirmative-action laws for women and minorities?

Responses:

Favor: $\quad 49 \%$

Oppose: $\quad 43 \%$

Don't know/Refused: $\quad 9 \%$

Population: National Adult

Population Size: 1022

Interview Method: Telephone

Survey Date: September 1994. 


\section{References}

Autor, D., A. Krueger and L. Katz, 1997, "Computing Inequality: Have Computers Changed the Labor Market?," NBER Working Paper No: 5956.

Coate, S. and G. Loury, 1993a, "Antidiscrimination Enforcement and the Problem of Patronization," American Economic Review, Papers and Proceedings, 83(2), May, 92-98.

Coate, S. and G. Loury, 1993b, "Will Affirmative-Action Policies Eliminate Negative Stereotypes?," American Economic Review, 83(5), December, 1220-40.

Fernandez, R. and J. Gali, 1997, "To Each According to...? Markets, Tournaments, and the Matching Problem with Borrowing Constraints," NBER Working Paper No: 5930, February.

Fernandez, R., 1998, "Education and Borrowing Constraints: Tests vs. Prices," unpublished manuscript.

Galor, O. and J. Zeira, 1993, "Income Distribution and Macroeconomics," Review of Economic Studies, April, 38(3-4), 817-26.

The Gallup Organization, http://www.gallup.com

Gradstein, M. and M. Justman, 1997, "Democratic Choice of an Education System: Implications for Growth and Income Distribution," Journal of Economic Growth, vol. 2, June, 169-83.

Glomm, G. and B. Ravikumar, 1992, "Public versus Private Investment in Human Capital: Endogenous Growth and Income Inequality," Journal of Political Economy, vol. 100, no. 4, 818-34.

Iyigun, M. F., forthcoming, "Public Education and Intergenerational Economic Mobility," International Economic Review.

Iyigun, M. F. and A. T. Levin, 1998, "Macroeconomic Implications of Competitive College Admissions," Board of Governors of the Federal Reserve System, IFDP No: 613.

Juhn, C., K. M. Murphy and B. Pierce, 1993, "Wage Inequality and the Rise in Returns to Skill," Journal of Political Economy, vol. 101, no. 3, 410-42. 
Lundberg, S. J., 1991, "The Enforcement of Equal Opportunity Laws Under Imperfect Information: Affirmative Action and Alternatives," Quarterly Journal of Economics, 106, February, 309-26.

Murphy, K. M., 1996, "Skills and Earnings Inequality: The Supply Side," AEI Seminar Series on Understanding Economic Inequality.

Welch, F., 1976, "Employment Quotas for Minorities," Journal of Political Economy, 84, August, S105-39. 


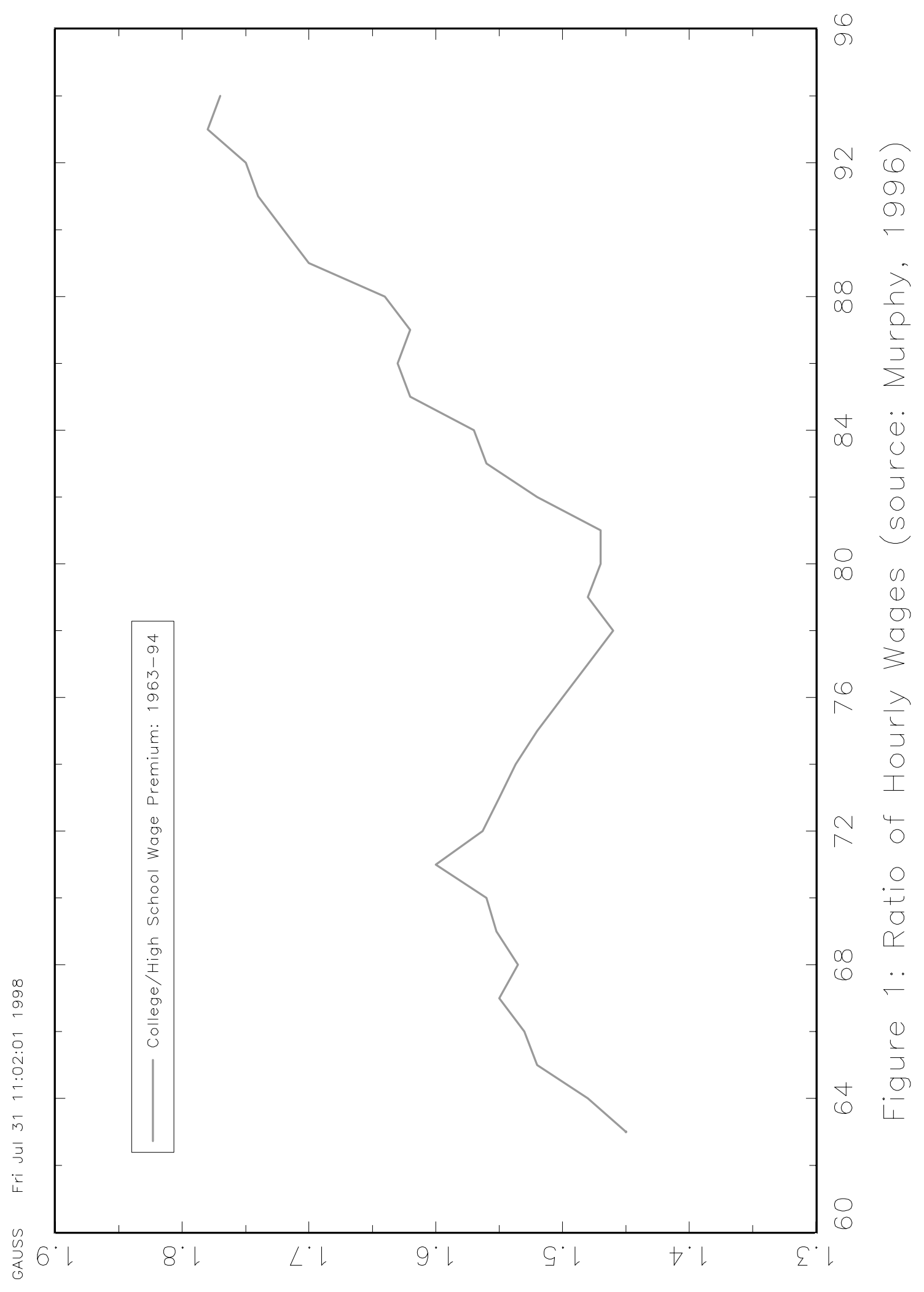




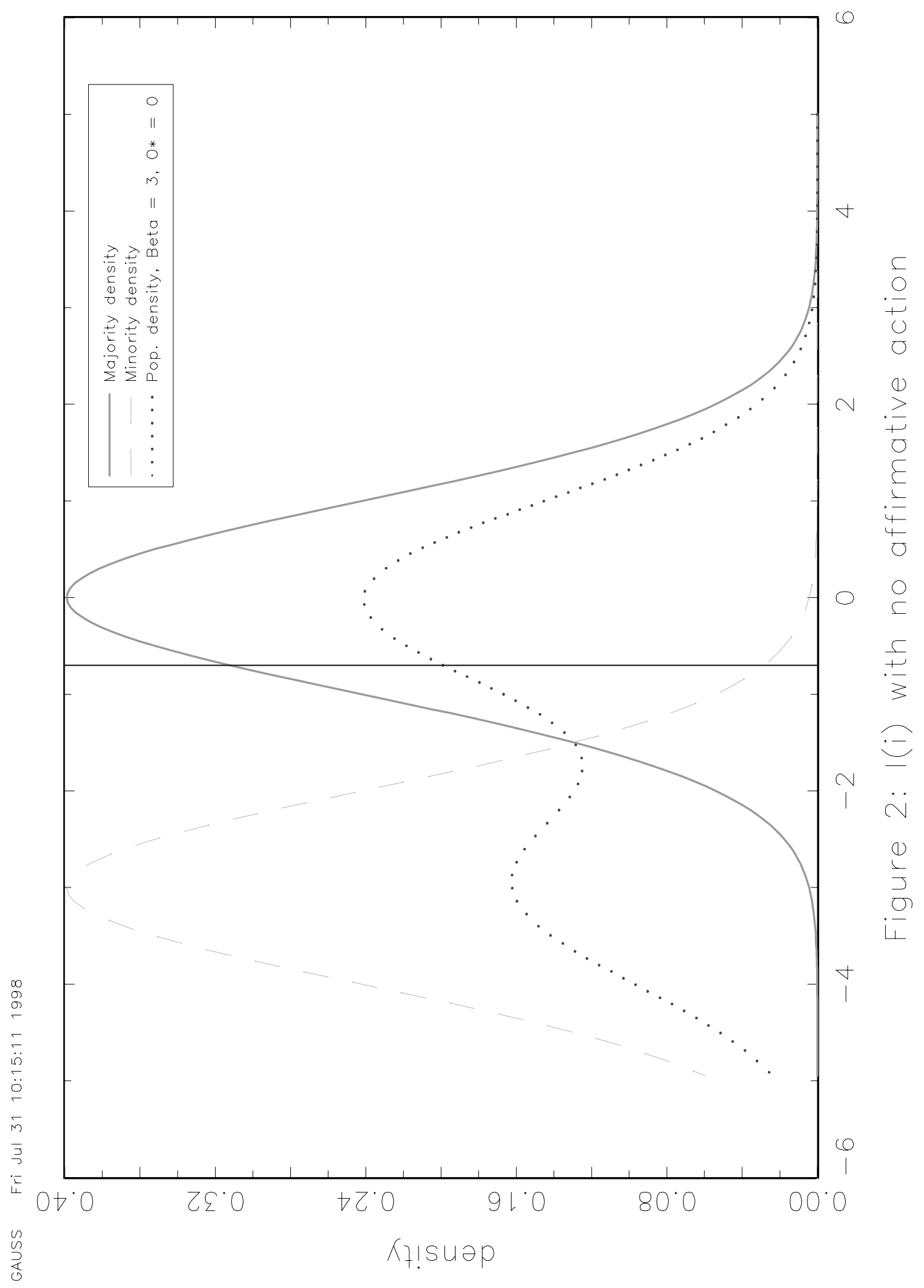




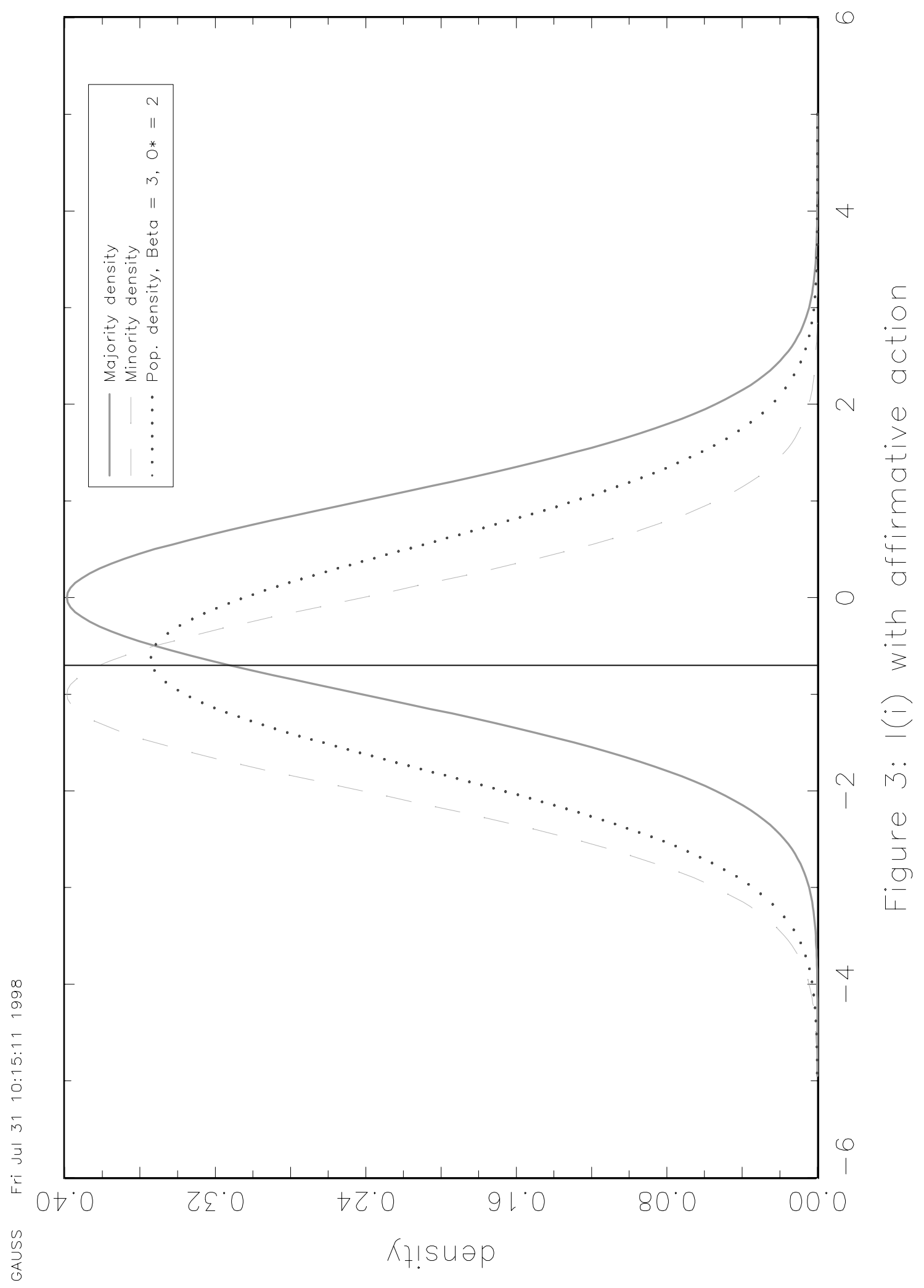




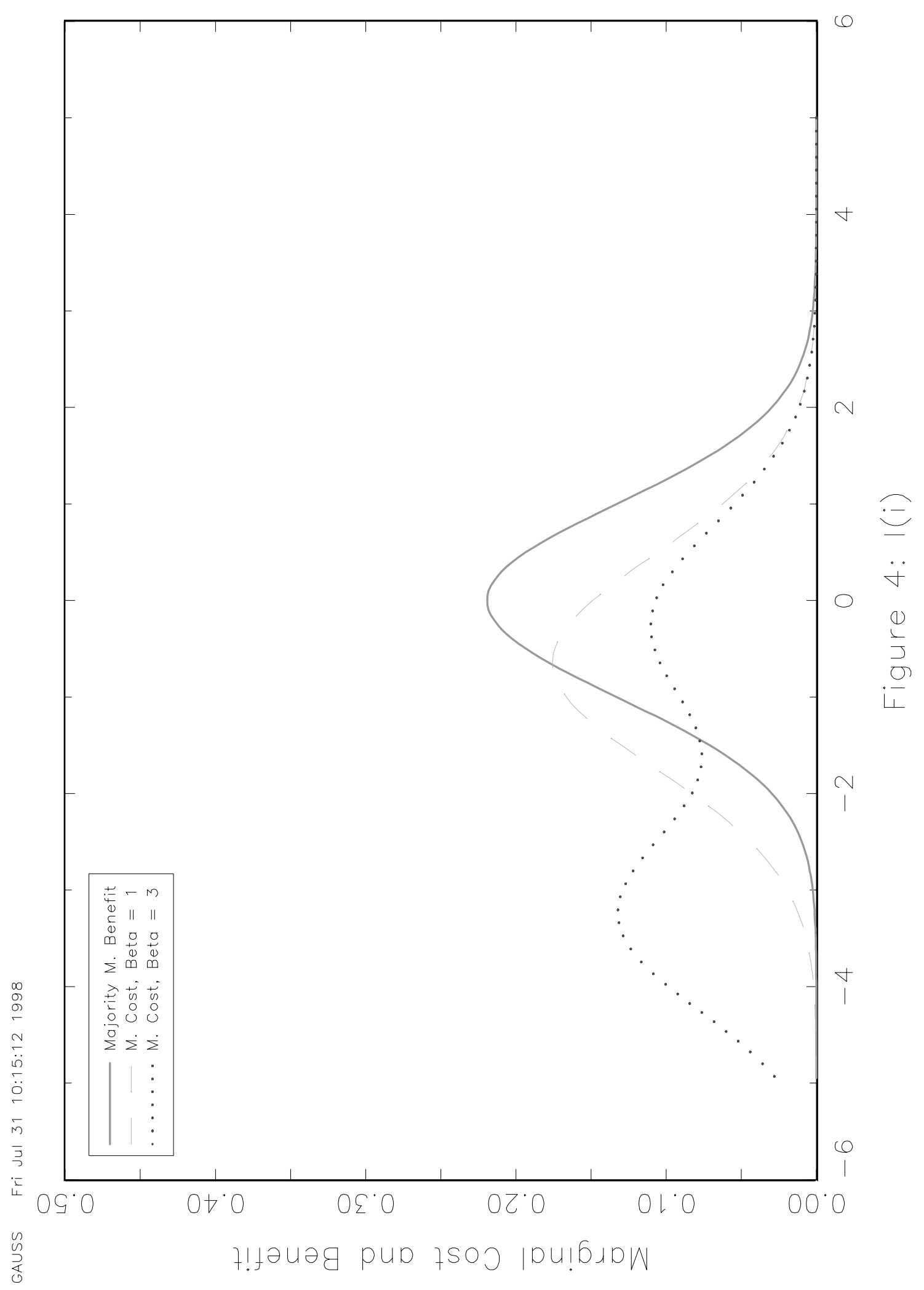

